\title{
An International Survey of Awareness of Genetic Risk in the Clinical Sarcoma Community
}

Kate A. McBride MPH (Hons) ${ }^{1,2}$; Timothy E. Schlub BSc (Hons), $\mathrm{PhD}^{1}$; Mandy L. Ballinger BSC (Hons), $\mathrm{PhD}^{3}$; David M. Thomas MBBS, $\mathrm{PhD}^{4}$; Martin H.N. Tattersall MD, ScD, MA ${ }^{5}$

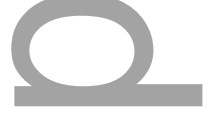

${ }^{1}$ School of Public Health, Sydney Medical School, University of Sydney, Camperdown 2006, NSW,

Australia; ${ }^{2}$ The Familial Cancer Service, Crown Princess Mary Cancer Centre, Westmead Hospital, Locked Bag, NSW 2145, Australia; ${ }^{3}$ Research Division, Peter MacCallum Cancer Centre, East Melbourne, VIC 3002, Australia; ${ }^{4}$ The Kinghorn Cancer Centre, Garvan Institute of Medical Research, Darlinghurst 2010, NSW, Australia; ${ }^{5}$ Department of Cancer Medicine, The Chris O'Brien Lifehouse, Sydney Medical School, University of Sydney, Camperdown 2006, NSW, Australia

Corresponding Author:

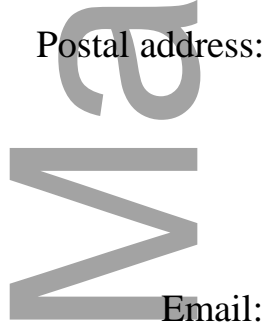

Telephone:

Fax:

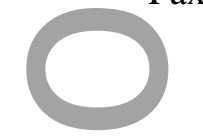

Kate A. McBride

L6 Nth, The Chris O’Brien Lifehouse C39Z

University of Sydney

NSW 2006

kate.mcbride@sydney.edu.au

0061286270174

0061290365292

Running title: Genetic risk awareness sarcoma physicians

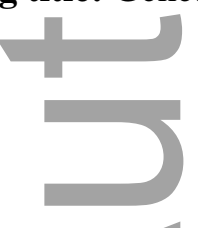

This is the author manuscript accepted for publication and has undergone full peer review but has not been through the copyediting, typesetting, pagination and proofreading process, which may lead to differences between this version and the Version of Record. Please cite this article as doi: 10.1111/ajco.12457.

This article is protected by copyright. All rights reserved. 
Aims: Integration of clinical genetics into oncology is variable. Sarcomas have a strong genetic component, with up to 1/30 patients carrying germline TP53 mutations. This study aimed to define genetic risk awareness amongst sarcoma physicians. Outcomes were attitudes towards genetic testing, level of cancer risk \& awareness of risk reduction measures.

Methods: An online survey was administered to members of the Connective Tissue Oncology Society and the Australasian Sarcoma Study Group.

Results: Sarcoma physicians (N=124) from 21 countries participated, $40 \%$ of whom favoured TP53 mutation testing in children regardless of family history, increasing to $\sim 83 \%$ for all age groups if a family history was present and $\sim 85 \%$ if multiple primary cancers were present. However $33 \%$ were not aware that risk reduction strategies might identify some cancers at a more curable stage in carriers. Conclusion: Clinical genetics is not yet standard of care for multidisciplinary management of sarcoma. Awareness of genetic risk is important amongst sarcoma physicians. Attitudes among the sarcoma community were generally positive, but education on genetic risk in sarcoma patients and collaboration with clinical genetics services might improve quality of care. Sarcoma physicians need routine access to clinical genetics services so that potential germline TP53 mutation carriers are recognized.

Keywords: Attitude; Genes, neoplasm; Hereditary Cancer Syndromes; Physician Practice Patterns; Sarcoma

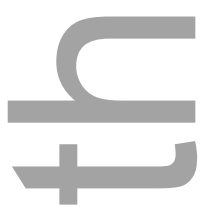

\section{Introduction}

This article is protected by copyright. All rights reserved. 
Integration of clinical genetics into oncology is variable for different cancer types and different patient age groups $(2,3)$. Genetic literacy also appears to differ among cancer specialties and identification of patients at high risk of carrying a germline mutation is variable in the oncology setting $(5,6)$. Many oncologists do not always consider possible familial or genetic aspects of their patient's cancer diagnosis. This may be because risk estimates are only available for certain genes and cancer types, such as seen in colorectal and breast cancer $(7,8)$. Over time specialists in these areas have accumulated sufficient data to allow incorporation of clinical genetics into their practice. The relatively high frequency of germline TP53 mutations in sarcoma patients is emerging (1) and awareness of this genetic risk is necessary for good clinical management.

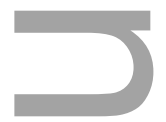

Sarcomas contribute disproportionately to the burden of cancer. They affect a young population, treatment is costly and prolonged and morbidity and mortality high. Sarcomas have a strong genetic component $(10,11)$ and identification of heritable risk is important for surveillance, treatment and reproductive decisions (18). New data indicate that 1/30 sarcoma patients may carry germline TP53 mutations (1). The prevalence of germline TP53 mutations in the general population is unknown. Failure to recognize the potential genetic risk in sarcoma patients may result in missed opportunities for screening and surveillance for patients and family members, both of which may improve outcomes. Several whole-body surveillance trials of germline TP53 mutation carriers are currently underway (18).

Germline TP53 mutations are associated with Li-Fraumeni Syndrome (21). This dominantly inherited syndrome is characterized by the high risk of cancer at multiple sites from early childhood through adulthood (4). Fifty per cent of carriers will develop cancer by the time they are 30 and $80 \%$ will develop cancer by the time they are 50 (9). The most frequent cancers are sarcoma (soft tissue and osteosarcoma), breast cancer, leukemia, adrenal cortical carcinoma and brain tumors (22).

This article is protected by copyright. All rights reserved. 
Significantly, sarcomas contribute $25 \%$ of all germline TP53 associated cancers reported on the IARC database (23). Early data also indicate that the $73 \%$ of childhood anaplastic rhabdomyosarcoma cases carry a germline TP53 mutation, irrespective of family history (24). Of relevance to already diagnosed sarcoma patients is the $30 \%$ risk of developing a second primary malignancy within 30 years $(13,14)$. This may, in part, be due to therapeutic and ongoing surveillance radiation, with mounting evidence that ionizing radiation increases cancer risk synergistically in germline TP53 carriers $(19,20)$. Lastly, germline risk has implications for family members with offspring having a $50 \%$ chance of inheriting the mutation.

To our knowledge, there is no information on sarcoma physicians' awareness of cancer risk associated with germline TP53 mutations, their willingness to refer for routine genetic testing or their knowledge of risk reduction measures available for mutation carriers.

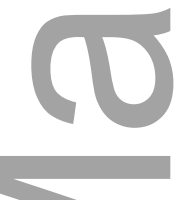

\section{Materials and methods}

A cross sectional online survey was sent to 2000 members of the Connective Tissue Oncology Society and the Australasian Sarcoma Study Group. The primary outcomes were attitudes towards genetic testing, knowledge of cancer risk and awareness of risk reduction measures.

\section{Survey instrument}

The survey was a 12 -item scale developed by an expert panel of clinical geneticists and sarcoma oncology professionals. The questionnaire was pilot tested on oncologists affiliated with Westmead Hospital in NSW, Australia and modified accordingly. These physicians were not included in the final sample. Consent to survey participation was inferred by completion of the questionnaire.

This article is protected by copyright. All rights reserved. 


\section{Statistical Analyses}

Descriptive statistics were calculated for independent variables (clinician age, gender, subspecialty \& country of practice). In the survey, each clinician is asked whether they would favour genetic testing (yes/no) and whether they would be in favour of whole body MRI (yes/no) in a number of scenarios including different patient ages and patient family history. To adjust for correlated responses within a clinician, we used a generalized linear mixed model with a binomial distribution of errors and logit link function. In this model we included sub-speciality, country of work, gender of clinician, age of clinician, clinician estimation of cancer risk in carriers, clinician belief in proven risk reduction strategies for earriers, age of patient, family history of patient, cancer risk, and single sarcoma or multiple malignancies as potential predictors of willingness to refer to genetic testing, and in being in favour of screening with whole-body MRI (WB-MRI) in TP53 mutation carriers. A process of backward elimination and forward addition was used to check the significance of fixed effects in the full model. All fixed effects in the full model had the similar significance values and odds ratios as in reduced models. The intercept, patient age and scenario were included as random effects and this was chosen to minimise the Akaike Corrected Information Criterion. Binary logistic regression was used to assess whether sub-speciality, clinician age, gender and geographic location were associated with knowledge of genetic risk and knowledge of proven strategies to reduce risk for carriers. All analyses were conducted in SPSS 21 (25).

\section{Results}

\section{Respondents}

Respondents were 159 of 2000 (7.95\%) people in 21 countries, 124 were sarcoma physicians (22 pediatric oncologists, 35 medical oncologists, 9 radiation oncologists and 58 surgeons). Other respondents included researchers $(9 \%)$, pathologists $(6 \%)$ and one clinical geneticist. Non-physicians and the clinical geneticist were excluded from the final analysis. The majority of respondents were

This article is protected by copyright. All rights reserved. 
male $(75 \%)$ and over the age of $40(77.4 \%)$ (Table 1). The low response rate may have been due to lack of clinician time or the complex subject matter.

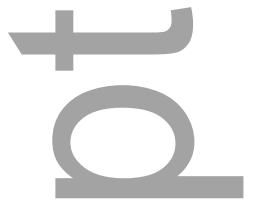

Table 1somewhere around here

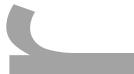

Willingness to refer for genetic testing

Rates of physician willingness to refer for TP53 genetic testing in the presence of a single sarcoma in young adults aged $16-25$ years were $33.9 \%$ and $21 \%$ in adults $>25$ years of age, with $40.3 \%$ of physicians favoring testing in children $<16$ years of age regardless of patient circumstance such as personal or family history (Table 3). Willingness to refer for genetic testing increased to $\sim 83 \%$ across all patient age groups if a family history of cancer was present, and $\sim 85 \%$ across all patient age groups if multiple primary cancers in a single individual patient had occurred. Country of practice and clinical scenario (single sarcoma, multiple malignancies, and family cancer history) were significant predictors of being in favor of referring for genetic testing. Physicians were more likely to favor genetic testing in patients with a strong family history or multiple malignancies compared to patients with a single sarcoma $(\mathrm{P}<0.0001$, family history $\mathrm{OR}=27.07$, multiple malignancies $\mathrm{OR}=31.47$ [Table 2]). Physician gender/age, subspecialty and whether the physician takes a family history were not significant predictors of being in favor of referral for genetic testing (Table 2). Physicians in Australia were more likely to be in favor of genetic testing $(\mathrm{P}=0.004, \mathrm{OR}=3.76,95 \% \mathrm{CI}=1.54$ to 9.20, [Table 2]). Most physicians (96\%) reported taking a family history (Table 3).

Table 2 here somewhere

Awareness of level of risk

This article is protected by copyright. All rights reserved. 
Less than half of physicians (41\%) (Table 3) estimated the cancer risk for TP53 mutation carriers by age 50 years accurately ( $>60 \%$ by age 50 ) with no significant differences between, age, gender or geographical region of the physician. There was trend for (pediatric oncologists to be able to accurately estimate cancer risk $(\mathrm{P}=0.085, \mathrm{OR} 2.67,95 \% \mathrm{CI}=0.87$ to 8.16 [Table 4]). Conversely $37 \%$ of physicians thought that the cancer risk was $<40 \%$ with this group including older physicians, surgeons and physicians from the Asia Pacific region (including Australia).

\section{Table 3 here somewhere}

\subsection{Risk reduction measures}

Thirty-three per cent of physicians were not aware that strategies exist that could reduce cancer risk in TP53 mutation carriers (Table 3), such as surveillance for early detection of cancers and risk reducing surgery in the case of breast cancer (Box 1$)$.

More than half of physicians (57\%) were not aware of reproductive technologies to reduce the risk of the mutation being passed on (Table 3), though pediatric oncologists were most likely to be aware of these strategies $(\mathrm{P}=0.023$, OR 3.22, 95\% CI $=1.17$ to 8.79 [Table 4] $)$. However, when told of these strategies (pre-natal testing such as amniocentesis and pre-implantation genetic diagnosis [PGD]), nearly half of physicians (47\%) considered them to be acceptable. Being a physician practicing in Australia was significantly associated with being in favor of pre-natal technologies $(\mathrm{P}=0.007, \mathrm{OR}$ $4.64,95 \% \mathrm{CI}=1.51$ to 14.25 [Table 4]). Female physicians were significantly more in favor of PGD than males $(\mathrm{P}=0.018$, OR $3.26,95 \% \mathrm{CI}=1.23$ to 8.64 [Table 4] $)$

Attitudes towards WB-MRI surveillance

This article is protected by copyright. All rights reserved. 
Nonetheless, $\sim 70 \%$ of physicians were in favor of whole body MRI (WB-MRI) as a surveillance modality in all patient age groups. Cluster analysis found that younger physicians ( $<40$ years of age) were significantly more likely to favor WB-MRI across all patient age groups ( $\mathrm{P}=<0.0001$, OR 4.51 , $95 \% \mathrm{CI}=2.00$ to 10.56 [Supplementary Table 1]). Cluster analysis did not reveal any significant associations with being in favor of WB-MRI across subspecialty, geographical region, patient age, physician gender, physician ability to estimate cancer risk and physician awareness of proven strategies (Supplementary Table 1). Binary logistic regression, however, revealed that being a pediatric oncologist was significantly associated with favoring WB-MRI in children < 16 years of age $(\mathrm{P}=0.038, \mathrm{OR} 3.29,95 \% \mathrm{CI}=1.07$ to $10.13[$ Table 4$])$.

\section{Discussion}

This international survey aimed to investigate sarcoma physicians' willingness to refer for routine genetic testing, their knowledge of risk reduction measures available for TP53 mutation carriers, and their knowledge of cancer risk in association with germline TP53 mutations.

We found that the majority of physicians were significantly in favor of referral for genetic testing where there was a personal history of multiple malignancies ( $80 \%$ in children $<16$ years old, $83 \%$ for 16-25 year olds) and/or a family cancer history ( $80 \%$ for testing in adults and $87 \%$ in children and young adults $<25$ years of age). Australian physicians were significantly more likely to be willing to refer for genetic testing in all cases. These results indicate that many sarcoma physicians have some awareness of 'red flag' personal and family histories that may indicate the presence of a germline TP53 mutation.

This article is protected by copyright. All rights reserved. 
Consistent with other research (26), we found that $96 \%$ physicians reported taking a family history and that a high proportion would favor routine genetic testing where there was a family history of cancer $(87 \%)$. However, we do not see these data reflected in actual referrals to the Family Cancer Clinic in the International Sarcoma Kindred Study data. This is relevant as family history taking is key to delivering the best preventative services to those most at risk (27). It has previously been shown that only $43 \%$ of patients at risk for colorectal (CRC) and breast cancers had their risk documented in their medical chart but that the age of cancer diagnoses in relatives was frequently missing (27). Furthermore, incomplete or sub-optimal family history taking due to factors such as competing patient diagnoses, low provider/patient time and communication problems between the clinician and the patient may also exist (27).This missing information can significantly impact the identification of at risk individuals.

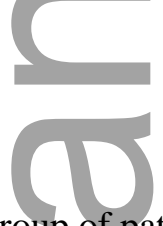

Another group of patients who may not be identified as being at risk are those with a single sarcoma. There were low rates of willingness to refer in the presence of a single sarcoma with only $40 \%$ of physicians in favor for children $<16$ years of age. This rate decreased as patient age increased (16-25 years $33.9 \%,>25$ years $25 \%$ ). The ISKS found that $40 \%$ of their probands with a germline TP53 mutation had only a single sarcoma with no personal or family history of cancer. Furthermore, $24 \%$ of germline TP53 mutations detected are de novo $(28,29)$. It may be that physicians are not fully aware of this data or of the possible advantages of referral to genetics services in the context of a single sarcoma. Physicians may also be limited in their ability to refer patients because of clinical guidelines for referral or payer issues where genetics services are not government funded.

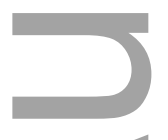

The former may be more likely given that $33 \%$ of physicians did not know that risk reduction strategies such as risk reducing surgery (for breast cancer) and pre-natal technologies are available for

This article is protected by copyright. All rights reserved. 
TP53 germline mutation carriers. Physicians may not be fully aware of the TP53 associated spectrum of cancers (Box 1). Furthermore it seems that physicians do not perceive surveillance, such as with WB-MRI, as a potential risk reduction measure. Younger physicians favored WB-MRI across all age groups indicating that there may be differences in attitude between physicians of different ages. Pediatric oncologists were also significantly more likely to be in favor of WB-MRI in sarcoma patients $<16$ years of age possibly because there is increasing awareness of the need for alternative screening methods in children due to the growing evidence of the late effects of other screening modalities such as CT/PET that use ionizing radiation $(30,31)$.

Many physicians (57\%) were not aware that pre-natal technologies could provide opportunity for offspring free of the risk allele. This is consistent with previous assessments of clinician knowledge of pre-natal technologies (32). When told what these pre-natal technologies entailed, some physicians found this technology to be acceptable (47\%) suggesting there may be concerns amongst sarcoma physicians about the use of pre-natal technologies. This may reflect a lack of familiarization with the options available. Pediatric oncologists were significantly in favor of these technologies compared to other specialties. The reasons for this are not clear though potentially this may be due to pediatric oncologists experiencing the everyday reality of treating very ill children therefore the potential to avoid that situation is welcomed.

Only $41 \%$ of physicians were able to accurately predict cancer risk in germline TP53 mutation carriers by the age of $50(\sim 60 \%)$. Approximately $1 / 3$ of physicians (37\%) underestimated the risk of TP53 associated cancers revealing a lack of awareness with low estimates made by surgeons, residents of Asian Pacific region and older physicians. Even though a strong association of sarcomas with Li-Fraumeni syndrome has been established since the early 1990s $(21,33)$, the translation of this knowledge to sarcoma physicians responsible for referring potential carriers for genetic testing

This article is protected by copyright. All rights reserved. 
appears to have been limited. This is meaningful when considering that deficiencies in clinician knowledge of genetics have been linked with referral practices in the past $(26,34)$ and indicates that a knowledge update may be warranted.

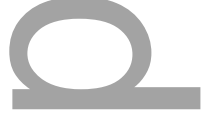

The findings indicate that knowledge around possible risk reduction for carriers, their families and potential offspring is limited. Physicians may be more likely to refer sarcoma patients for genetic testing if physicians had a more complete understanding of TP53 associated genetic risk and possible risk reduction strategies. Furthermore, sarcoma physicians appear to not take into account the high de novo rate of germline TP53 mutations.

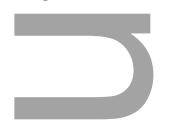

There may be other reasons for non-referral to clinical genetics services: sarcoma physicians may not be aware that clinical genetics services are widely available with expertise to assist in the long-term management of these patients and their families. It has been shown previously that half of doctors did not know of a geneticist or genetic counselor (35) and that communication between primary care physicians and the genetics community is far from optimal (36). Other impediments to accessing genetics services could include clinical nihilism towards testing for germline TP53 mutations by the genetics services themselves. In the past genetic testing for TP53 was widely regarded as futile because the clinical utility of the information was felt to be very limited. This perspective is slowly changing as surveillance strategies are increasingly being investigated (16). A lack of local comprehensive genetic testing services is also possible, though only $8 \%$ of respondents in this survey are from countries outside of North America, Western Europe and Australasia where such services may be lacking. Finally, treating oncologists could also feel that there is no perceived benefit for their patient, perhaps not considering the potential wider benefits for family members. A recent study on factors influencing the organizational adoption of genetics services found that clinical genetics services were not seen to be advantageous to their patients or that they would have a high clinical

This article is protected by copyright. All rights reserved. 
impact (37).This explanation seems likely in this sample of physicians as reflected by the low awareness of risk reduction strategies and pre-natal technologies. Because clinical genetics are not yet standard care for the multidisciplinary management of sarcoma, an increased awareness of genetic risk is important among sarcoma physicians.

It is important to increase physician awareness of the likelihood of germline TP53 mutations in sarcoma patients. An initial measure to achieve this would be to ensure a comprehensive family history taking that should identify patients at most obvious risk. This could be done through the use of standardized family history taking tools with scores based on personal and family history. Tools like these have been shown to be promising (38). Patient education on the importance of family history could also be useful with patients requested to complete pre-appointment family history questionnaires with an explanation as to why this is important. This would also allow the focus during appointments to remain on the primary diagnosis rather than family history taking.

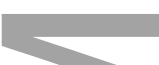

Another avenue for addressing the lack of awareness of germline TP53 mutations could be via multidisciplinary team meetings (MDTs). The clinical genetics services could be involved and on hand to help identify potential TP53 carriers. In this setting, the clinical geneticists could provide ongoing and current knowledge of available genetics services, risk reduction strategies, red flag personal and family histories that may indicate possible mutation carriers. This best practice collaboration may assist not only with the identification of at-risk individuals and their families but also strengthen links between the sarcoma clinic and the clinical genetics services, which will be crucial as our understanding of the heritable genetic drivers of sarcoma increases in the future.

For this or other strategies to be implemented, however, there needs to be consultation with sarcoma physicians on how best to integrate clinical genetics into their practice. The views of

This article is protected by copyright. All rights reserved. 
patients should also be taken into consideration as they may help to guide how this additional information can best be handled. Literature exists about the views of breast cancer patients on rapid testing and how this impacts on treatment decisions and patient awareness of risk (39); this could guide the most effective integration of clinical genetics into sarcoma management conferring the most benefit to patients. There is potentially a role for rapid genetic testing due to the growing body of evidence that TP53 mutations cause radiation sensitivity due to impaired recognition and repair of DNA damage $(40,41)$. Treatment with radiotherapy could be avoided in these patients if other treatment modalities with comparable cure rates are available.

For several years heritable genetic factors contributing to colorectal cancer and breast cancer have been recognized. Physicians in these areas have a comprehensive knowledge of possible contributing genetic faults in these cancers, are aware of risk reduction strategies and have clinical genetics services as part of their MDTs. This has led to improvements in both treatment and surveillance/risk reduction measures and, as a consequence improved overall survival for hereditary related breast and colorectal cancers $(42,43)$. In the sarcoma field awareness of contributing genetic factors and inclusion of clinical genetics services is at very early stage but moving forward it could be modeled on the breast cancer and colorectal cancer frameworks for care.

Attitudes to genetic counseling and risk reduction measures among the sarcoma community were generally positive. Education on the implications of germline TP53 mutations and opportunities for genetic risk modification may improve quality of care. Many physicians are not aware that genetic counseling and testing can provide information to the family that may help in reducing morbidity and

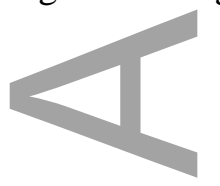

This article is protected by copyright. All rights reserved. 
mortality associated with germline TP53 mutations. Further research is needed on how best to accomplish this and to establish patient preferences.

\section{Conclusion}

Sarcoma physicians do not yet have a detailed knowledge of the contribution of germline TP53 mutations to the hereditary aspects of sarcoma. Referral by sarcoma physicians to clinical genetics services is necessary if potential germline TP53 mutation carriers are to be identified. This knowledge, coupled with an increased awareness of risk reduction strategies and reproductive technologies, may improve clinical management of TP53 mutation carriers and impact positively on the morbidity and mortality associated with sarcoma. Future directions in this area should include patient preferences on timing and the offer of clinical genetics services. Educational materials for sarcoma physicians on TP53 and risk reduction measures/availability of clinical genetics also need to be developed, effective family history taking tools evaluated and research conducted on how best to increase interdisciplinary collaboration between sarcoma oncologists and clinical genetics services.

\section{Limitations}

This study had a limited response rate and may not be a representative sample as physicians who already had an interest in TP53 and some knowledge may have been more likely to respond. This could skew results towards higher rates of willingness to refer for genetic testing and higher knowledge around cancer risk in association with this mutation. Nonetheless, this survey provides important groundwork in this field.

\section{Acknowledgements}

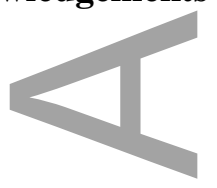

This article is protected by copyright. All rights reserved. 
The Australasian Sarcoma Study Group and the Connective Tissue Oncology Society for permitting this survey to be emailed to their members. The National Health and Medical Research Council for providing a postgraduate scholarship support for K. McBride.

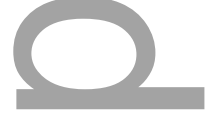

Conflict of interest: the authors declare no conflict of interest.

\section{References}

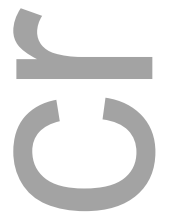

1. Mitchell G, Ballinger ML, Wong S, Hewitt C, James P, Young M-A, et al. High Frequency of Germline TP53 Mutations in a Prospective Adult-Onset Sarcoma Cohort. PloS one. 2013;8(7):e69026-e.

2. Kaye C, Korf B. Genetic Literacy and Competency. Pediatrics. 2013;132:S224-S30.

3. Ready KJ, Daniels MS, Sun CC, Peterson SK, Northrup H, Lu KH. Obstetrics/Gynecology Residents' Knowledge of Hereditary Breast and Ovarian Cancer and Lynch Syndrome. Journal of Cancer Education. 2010;25(3):401-4.

4. Nichols KE, Malkin D, Garber JE, Fraumeni JF, Li FP. Germ-line p53 mutations predispose to a wide spectrum of early-onset cancers. Cancer Epidemiology Biomarkers \& Prevention. $2001 ; 10(2): 83-7$

5. Schroy PC, Barrison AF, Ling BS, Wilson S, Geller AC. Family history and colorectal cancer screening: A survey of physician knowledge and practice patterns. American Journal of Gastroenterology. 2002;97(4):1031-6.

6. Wideroff L, Vadaparampil ST, Greene MH, Taplin S, Olson L, Freedman AN. Hereditary breast/ovarian and colorectal cancer genetics knowledge in a national sample of US physicians. Journal of Medical Genetics. 2005;42(10):749-55.

7. Brohet RM, Velthuizen ME, Hogervorst FBL, Meijers-Heijboer HEJ, Seynaeve C, Collee MJ, et al. Breast and ovarian cancer risks in a large series of clinically ascertained families with a high proportion of BRCA1 and BRCA2 Dutch founder mutations. Journal of Medical Genetics.

2014;51(2):98-107.

8. Theodoratou E, Campbell H, Tenesa A, Houlston R, Webb E, Lubbe S, et al. A large-scale meta-analysis to refine colorectal cancer risk estimates associated with MUTYH variants. British Journal of Cancer. 2010;103(12):1875-84.

This article is protected by copyright. All rights reserved. 
9. Lustbader ED, Williams WR, Bondy ML, Strom S, Strong LC. Segregation analysis of cancer in families of childhood soft-tissue-sarcoma patients. American Journal of Human Genetics. 1992;51(2):344-56.

10. Olivier M, Hollstein M, Hainaut P. TP53 Mutations in Human Cancers: Origins, Consequences, and Clinical Use. Cold Spring Harbor Perspectives in Biology. 2010;2(1).

11. Mai PL, Malkin D, Garber JE, Schiffman JD, Weitzel JN, Strong LC, et al. Li-Fraumeni syndrome: report of a clinical research workshop and creation of a research consortium. Cancer genetics. 2012;205(10).

12. Petitjean A, Mathe E, Kato S, Ishioka C, Tavtigian SV, Hainaut P, et al. Impact of mutant p53 functional properties on TP53 mutation patterns and tumor phenotype: Lessons from recent developments in the IARC TP53 database. Human Mutation. 2007;28(6):622-9.

13. Hisada M, Garber JE, Fung CY, Fraumeni JF, Li FP. Multiple primary cancers in families with Li-Fraumeni syndrome. Journal of the National Cancer Institute. 1998;90(8):606-11.

14. Hwang SJ, Lozano G, Amos CI, Strong LC. Germline p53 mutations in a cohort with childhood sarcoma: Sex differences in cancer risk. American Journal of Human Genetics. 2003;72(4):975-83.

15. Varley JM, Evans DGR, Birch JM. Li-Fraumeni syndrome - A molecular and clinical review. British Journal of Cancer. 1997;76(1):1-14.

16. Villani A, Tabori U, Schiffman J, Shlien A, Beyene J, Druker H, et al. Biochemical and imaging surveillance in germline TP53 mutation carriers with Li-Fraumeni syndrome: a prospective observational study. Lancet Oncology. 2011;12(6):559-67.

17. Masciari S, Van den Abbeele AD, Diller LR, Rastarhuyeva I, Yap J, Schneider K, et al. F18fluorodeoxyglucose-positron emission tomography/computed tomography screening in Li-Fraumeni syndrome. Jama-Journal of the American Medical Association. 2008;299(11):1315-9.

18. McBride KA, Ballinger ML, Killick E, Kirk J, Tattersall MHN, Eeles RA, et al. Li-Fraumeni syndrome: cancer risk assessment and clinical management. Nature Reviews Clinical Oncology. 2014;11(5):260-71.

19. Kleinerman RA. Radiation-sensitive genetically susceptible pediatric sub-populations. Pediatric Radiology. 2009;39:S27-S31.

20. Heymann S, Delaloge S, Rahal A, Caron O, Frebourg T, Barreau L, et al. Radio-induced malignancies after breast cancer postoperative radiotherapy in patients with $\mathrm{Li}$-Fraumeni syndrome. Radiation Oncology. 2010;5.

21. Malkin D, Li FP, Strong LC, Fraumeni JF, Nelson CE, Kim DH, et al. Germ line p53 mutations in a familial syndrome of breast-cancet, sarcomas, and other neoplasms. Science. 1990;250(4985):1233-8.

This article is protected by copyright. All rights reserved. 
22. Petitjean A, Achatz MIW, Borresen-Dale AL, Hainaut P, Olivier M. TP53 mutations in human cancers: functional selection and impact on cancer prognosis and outcomes. Oncogene. 2007;26(15):2157-65.

23. Ognjanovic S, Olivier M, Bergemann TL, Hainaut P. Sarcomas in TP53 Germline Mutation Carriers A Review of the IARC TP53 Database. Cancer. 2012;118(5).

24. Hettmer S, Archer NM, Somers GR, Novokmet A, Wagers AJ, Diller L, et al. Anaplastic Rhabdomyosarcoma in TP53 Germline Mutation Carriers. Cancer. 2014;120(7):1068-75.

25. IBM.Corp. IBM SPSS Statistics for Windows, Version 21.0. Armonk, NY: IBM Corp.; 2012.

26. Hayflick SJ, Eiff MP, Carpenter L, Steinberger J. Primary care physicians' utilization and perceptions of genetics services. Genetics in Medicine. 1998;1(1):13-21.

27. Murff HJ, Greevy R, Syngal S. The comprehensiveness of family cancer history assessments in primary care. Community Genetics. 2007;10(3):174-80.

28. Kamihara J, Rana HQ, Garber JE. Germline TP53 Mutations and the Changing Landscape of Li-Fraumeni Syndrome. Human Mutation. 2014;35(6):654-62.

29. Gonzalez KD, Buzin CH, Noltner KA, Gu D, Li W, Malkin D, et al. High frequency of de novo mutations in Li-Fraumeni syndrome. Journal of Medical Genetics. 2009;46(10):689-93.

30. Klenk C, Gawande R, Uslu L, Khurana A, Qiu D, Quon A, et al. Ionising radiation-free whole-body MRI versus F-18-fluorodeoxyglucose PET/CT scans for children and young adults with cancer: a prospective, non-randomised, single-centre study. Lancet Oncology. 2014;15(3):275-85.

31. Chawla SC, Federman N, Zhang D, Nagata K, Nuthakki S, McNitt-Gray M, et al. Estimated cumulative radiation dose from PET/CT in children with malignancies: a 5-year retrospective review. Pediatric Radiology. 2010;40(5):681-6.

32. Brandt AC, Tschirgi ML, Ready KJ, Sun C, Darilek S, Hecht J, et al. Knowledge, attitudes, and clinical experience of physicians regarding preimplantation genetic diagnosis for hereditary cancer predisposition syndromes. Familial Cancer. 2010;9(3):479-87.

33. Li FP. Li-Fraumeni syndrome. American Journal of Human Genetics. 1991;49(4).

34. Hofman KJ, Tambor ES, Chase GA, Geller G, Faden RR, Holtzman NA. Physicians knowledge of genetics and genetic tests. Academic Medicine. 1993;68(8):625-32.

35. Haga SB, Burke W, Agans R. Primary-care physicians' access to genetic specialists: an impediment to the routine use of genomic medicine? Genetics in Medicine. 2013;15(7):513-4.

36. Taylor MRG, Edwards JG, Ku L. Lost in transition: Challenges in the expanding field of adult genetics. American Journal of Medical Genetics Part C-Seminars in Medical Genetics. 2006;142C(4):294-303.

This article is protected by copyright. All rights reserved. 
37. Hamilton AB, Oishi S, Yano EM, Gammage CE, Marshall NJ, Scheuner MT. Factors influencing organizational adoption and implementation of clinical genetic services. Genetics in Medicine. 2014;16(3):238-45.

38. de Hoog CLMM, Portegijs PJM, Stoffers HEJH. Family history tools for primary care are not ready yet to be implemented. A systematic review. European Journal of General Practice.

2014;20(2):125-33.

39. Wevers M, Ausems M, Bleiker E, Rutgers E, Witkamp A, Hahn D, et al. Psychosocial Impact of Rapid Genetic Counseling and Testing in Breast Cancer Patients: Findings From a RCT. PsychoOncology. 2013;22:25-6.

40. Ferrarini A, Auteri-Kaczmarek A, Pica A, Boesch N, Heinimann K, Schaefer SC, et al. Early occurrence of lung adenocarcinoma and breast cancer after radiotherapy of a chest wall sarcoma in a patient with a de novo germline mutation in TP53. Familial Cancer. 2011;10(2):187-92.

41. Henry E, Villalobos V, Million L, Jensen KC, West R, Ganjoo K, et al. Chest Wall Leiomyosarcoma After Breast-Conservative Therapy for Early-Stage Breast Cancer in a Young Woman With Li-Fraumeni Syndrome. Journal of the National Comprehensive Cancer Network. 2012;10(8):939-42.

42. Vasen HFA, Tomlinson I, Castells A. Clinical management of hereditary colorectal cancer syndromes. Nature Reviews Gastroenterology \& Hepatology. 2015;12(2):88-97.

43. Pruthi S, Gostout BS, Lindor NM. Identification and Management of Women With BRCA Mutations or Hereditary Predisposition for Breast and Ovarian Cancer. Mayo Clinic Proceedings. 2010;85(12):1111-20.

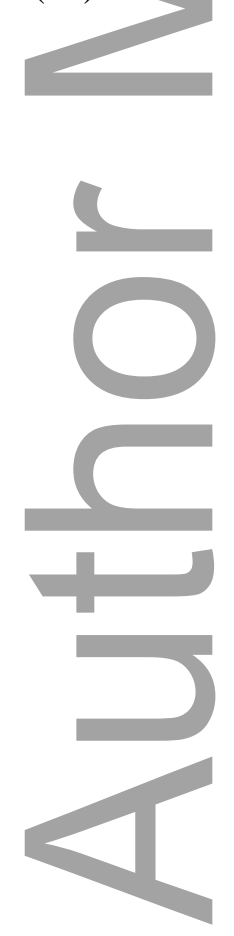

This article is protected by copyright. All rights reserved. 


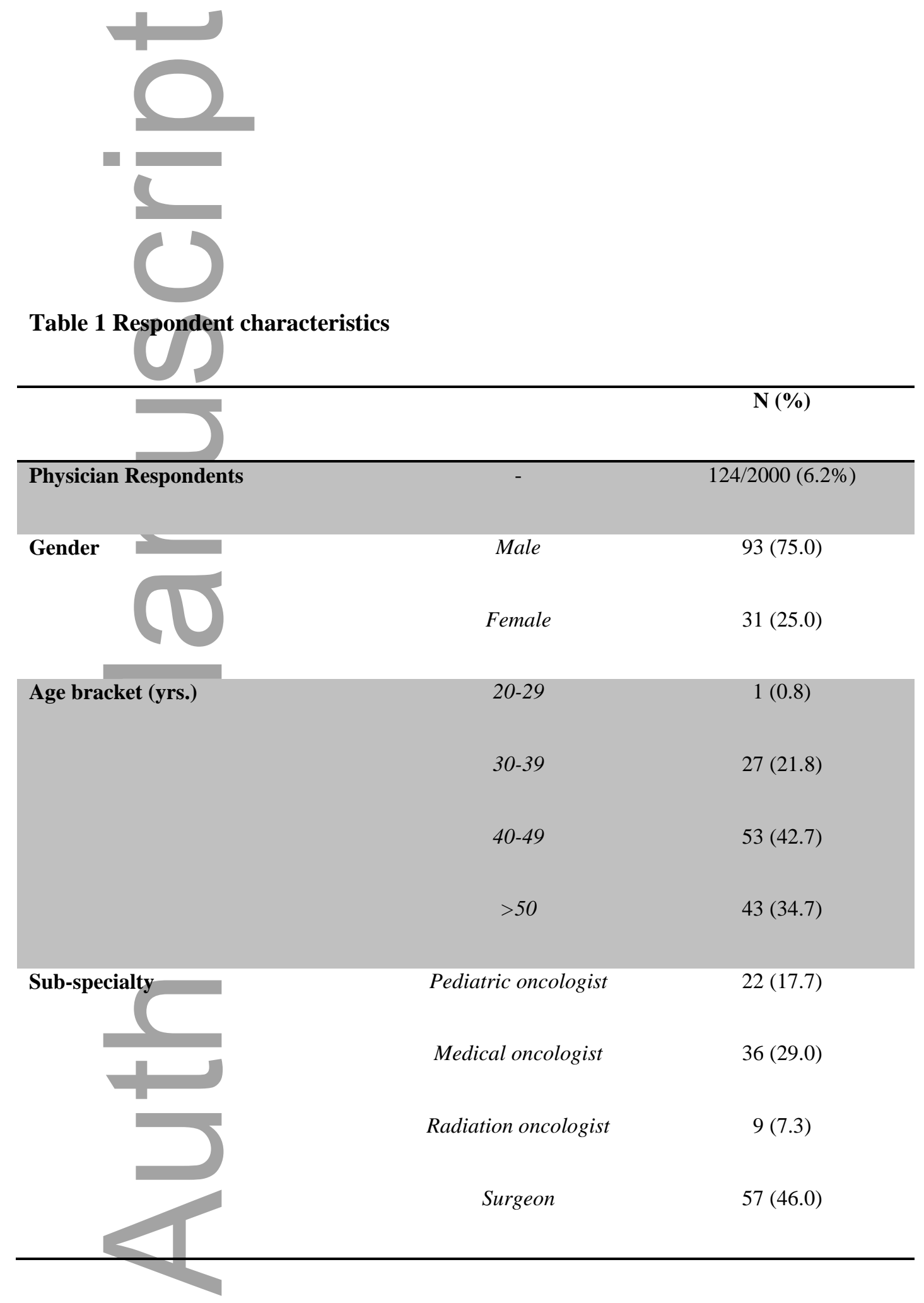

This article is protected by copyright. All rights reserved. 


\begin{tabular}{lcc}
\hline Geographical location & Asia Pacific & $29(23.4)$ \\
Europe & $22(17.7)$ \\
North America & $73(58.9)$ \\
Regularly takes family history & - & $119(96)$ \\
\hline
\end{tabular}

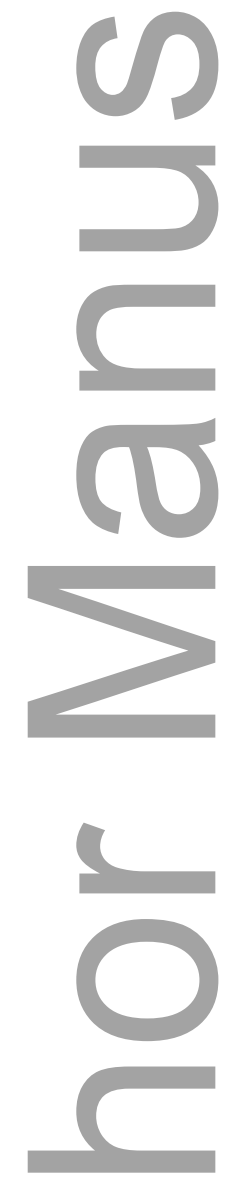

Table 2 Willingness to refer for genetic testing

\begin{tabular}{lcc}
\hline Variable & Odds ratio (95\% CI) & P-Value \\
\hline Physician Age & 0.644 \\
\end{tabular}

This article is protected by copyright. All rights reserved. 


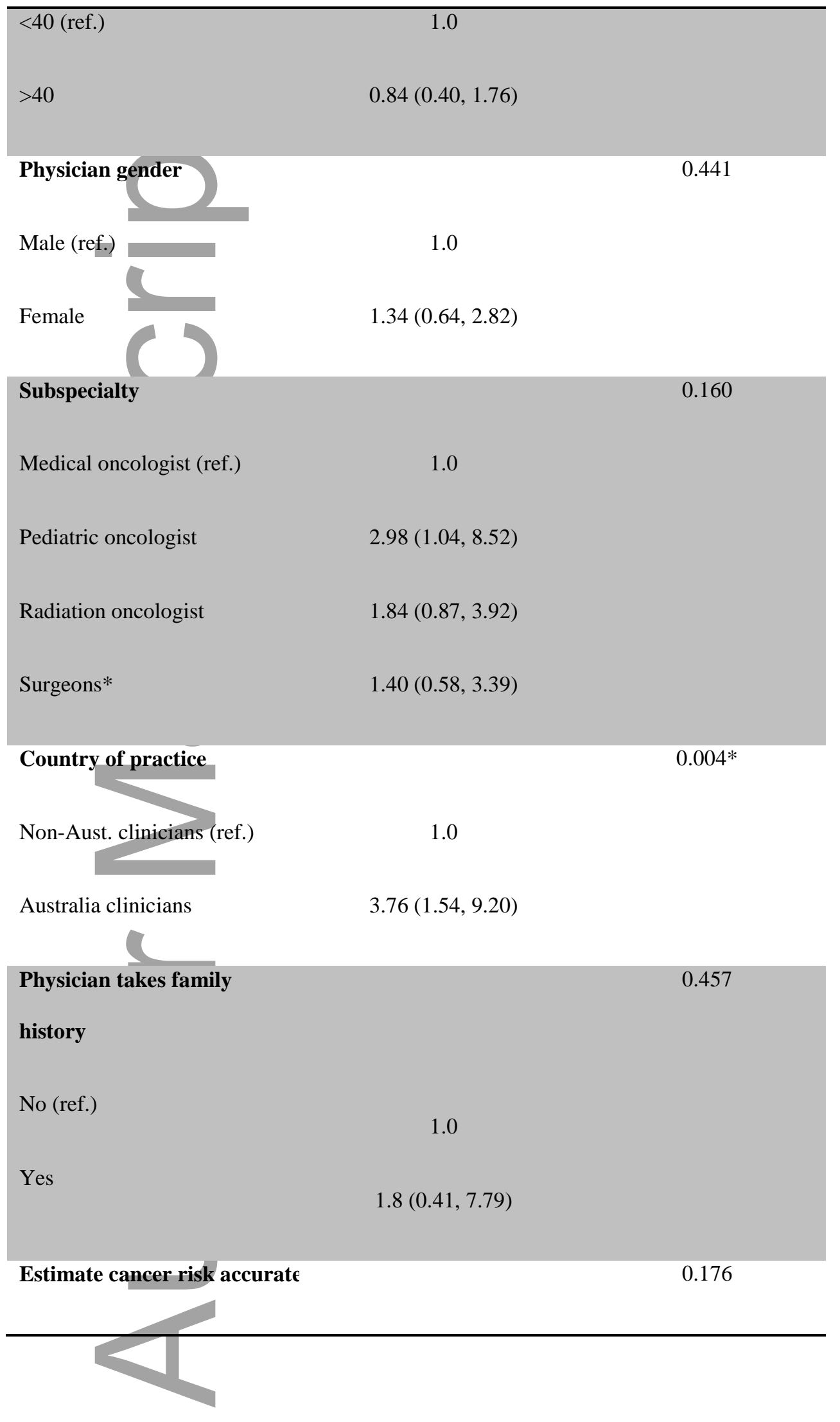

This article is protected by copyright. All rights reserved. 


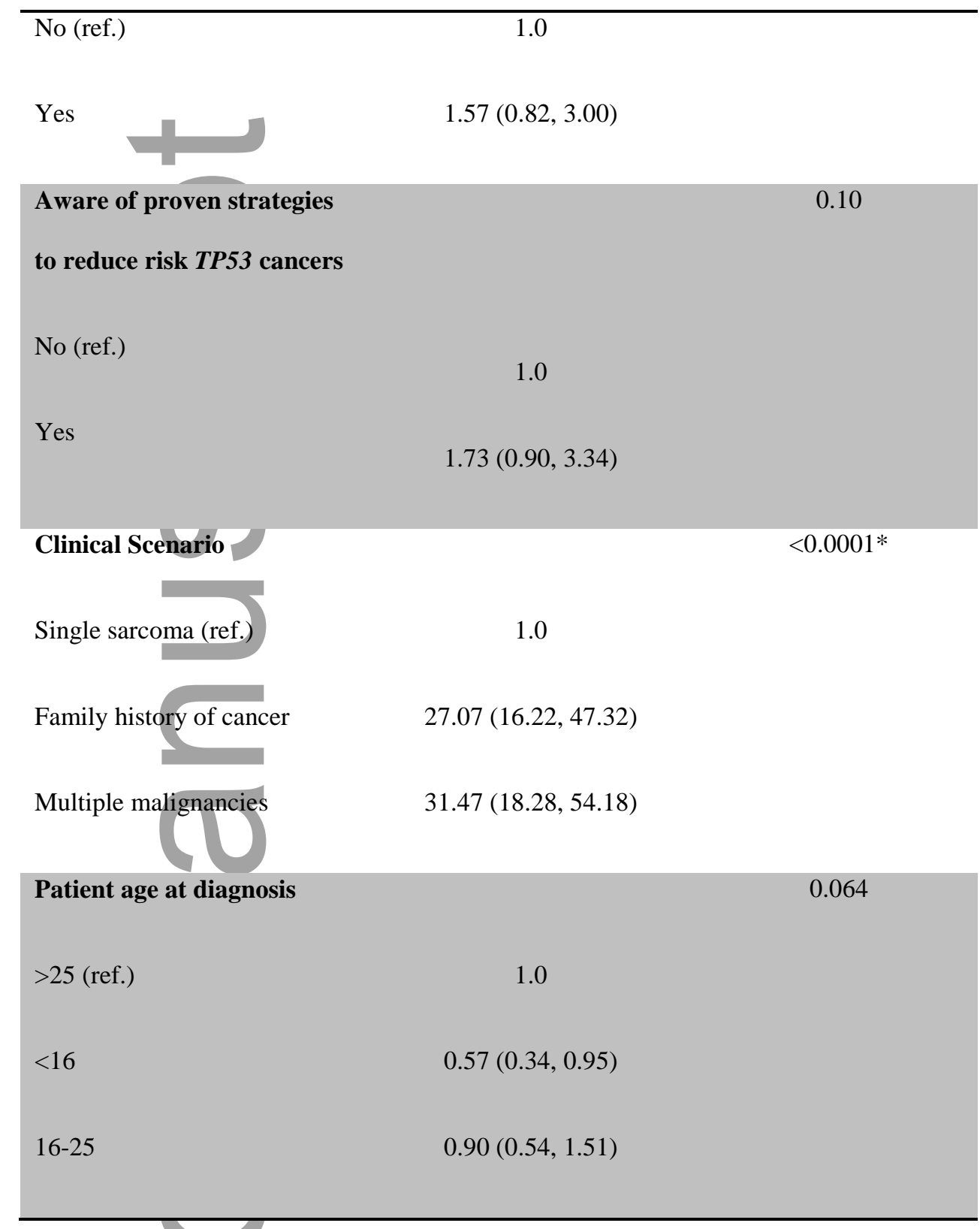

* Orthopedic and oncological surgeons

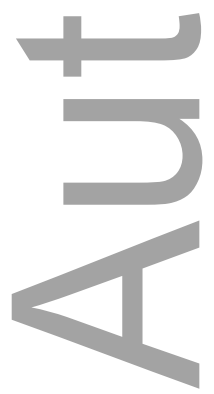

This article is protected by copyright. All rights reserved. 

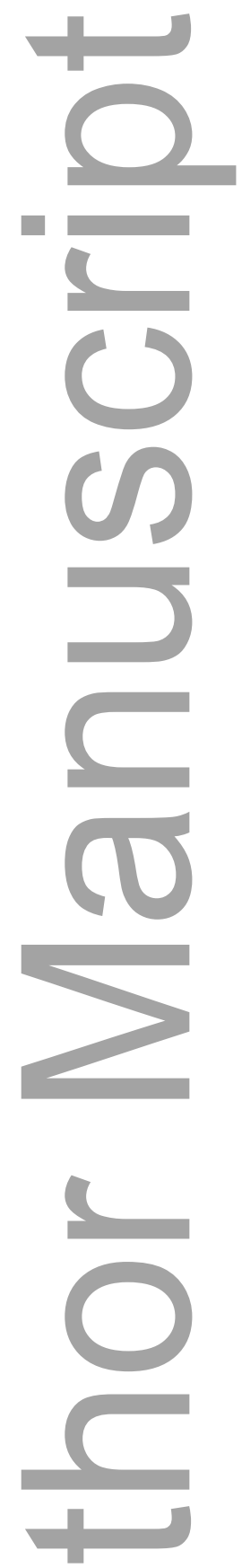

Table 3 Frequencies

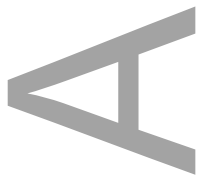

This article is protected by copyright. All rights reserved. 


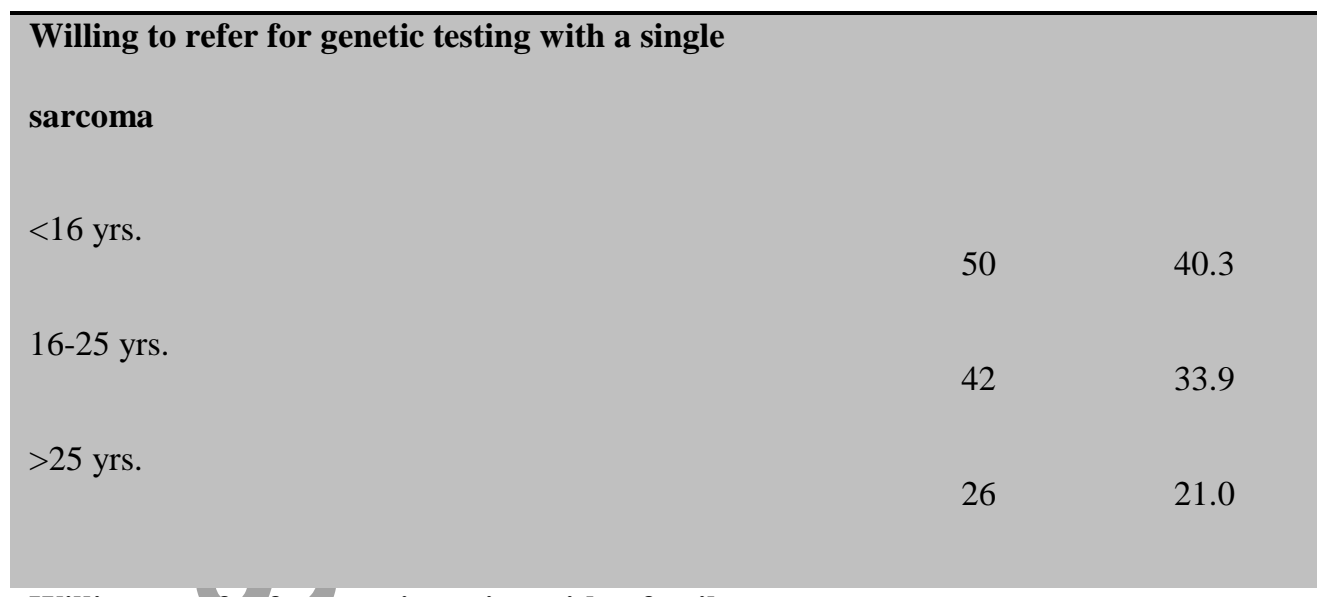

Willing to refer for genetic testing with a family

history of cancer

$<16$ yrs.

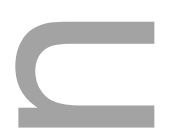

99

79.8

$16-25 \mathrm{yrs}$.

102

82.3

$>25$ yrs.

Willing to refer for genetic testing with multiple

malignancies

$<16$ yrs.

$16-25$ yrs.

This article is protected by copyright. All rights reserved. 


\begin{tabular}{|c|c|c|}
\hline Not aware of proven strategies to reduce risk $T P 53$ & 41 & 33.1 \\
\hline \multicolumn{3}{|l|}{ cancers } \\
\hline Not aware of reproductive technologies to reduce risk & 71 & 57.3 \\
\hline of having child with TP53 mutation & & \\
\hline
\end{tabular}

* Clinician ability to estimate the cancer risk for TP53 mutation carriers by age 50 years accurately (>60\% by age 50$)$

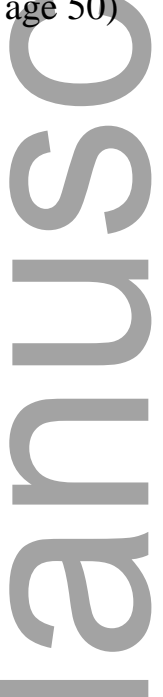

Table 4 Binary logistic regressions

OR $\quad 95 \%$ CI P value

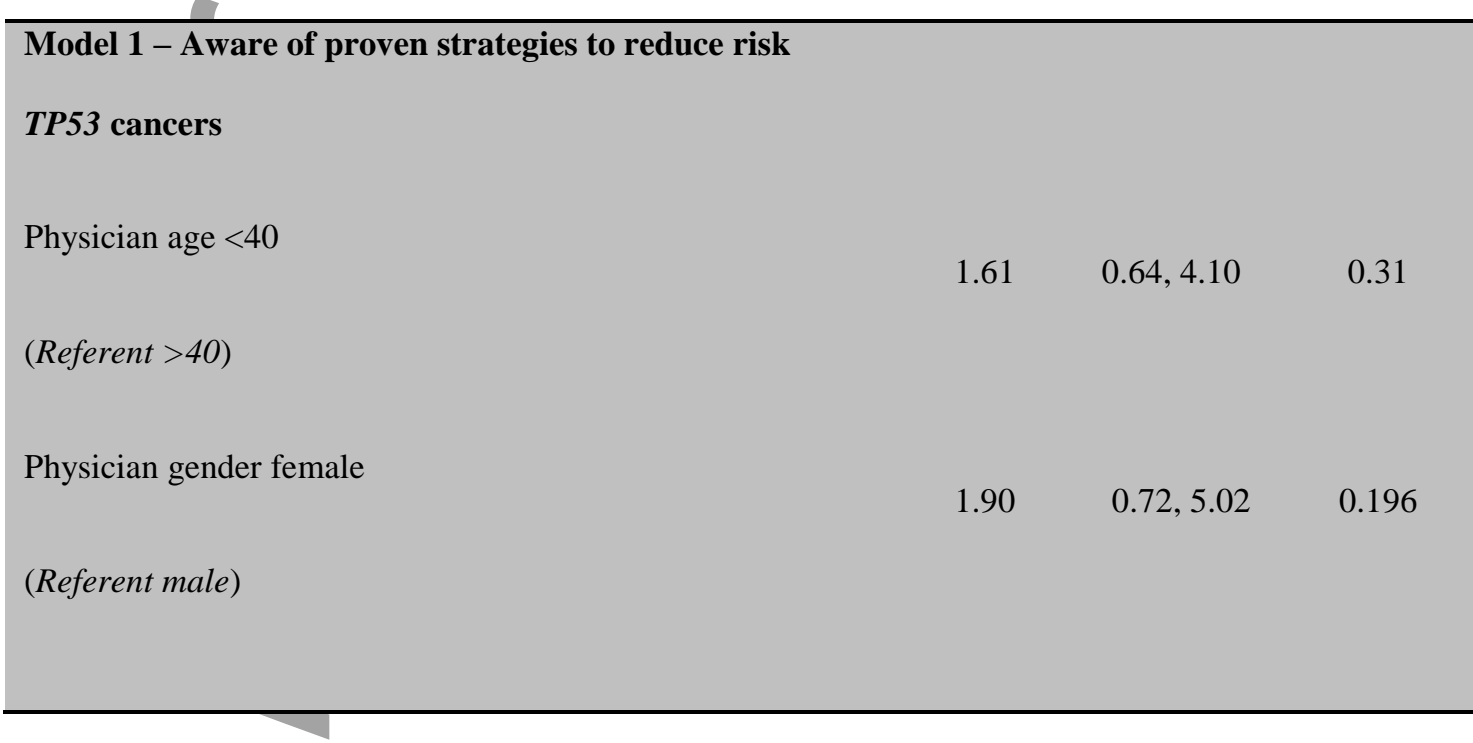

This article is protected by copyright. All rights reserved. 


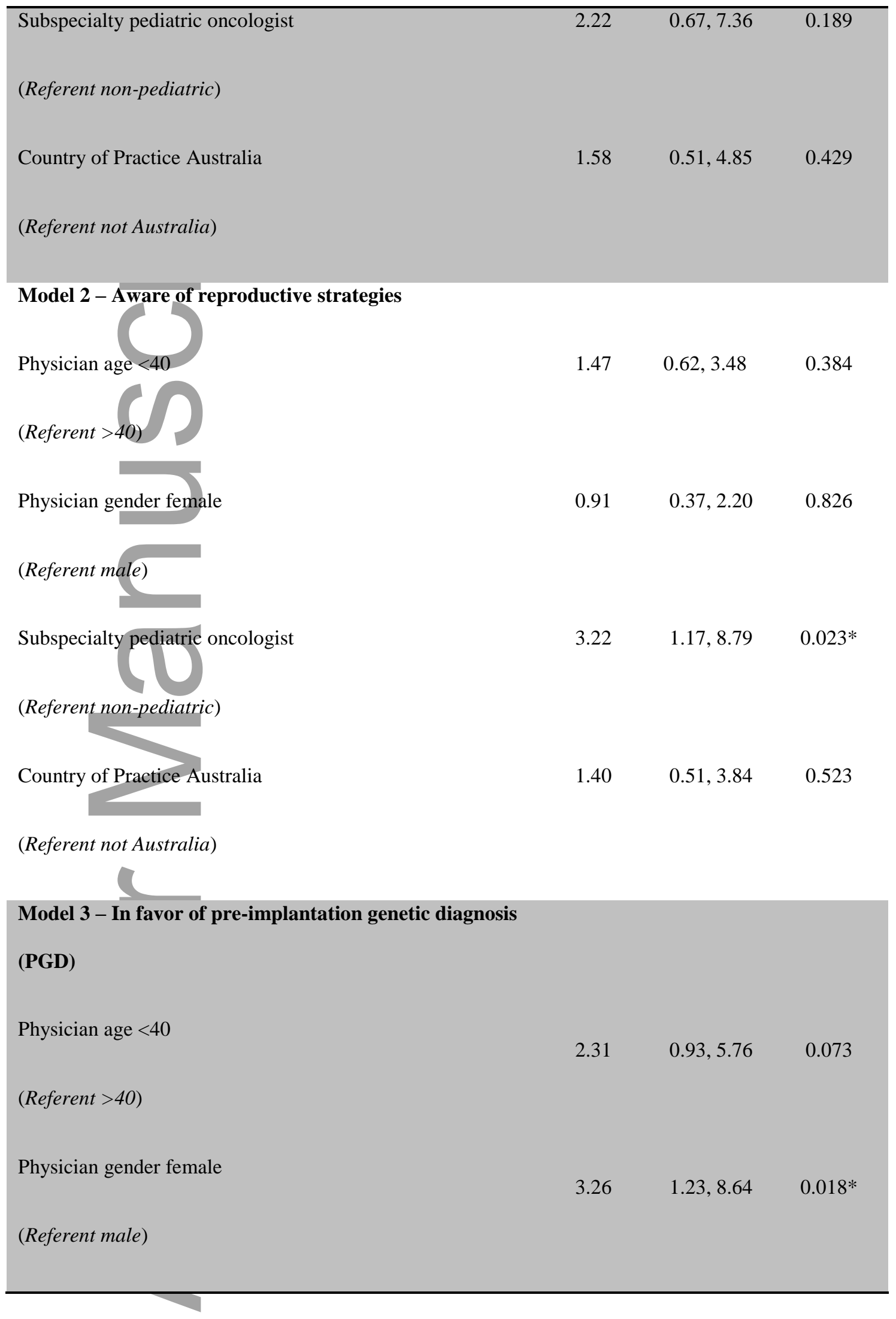

This article is protected by copyright. All rights reserved. 


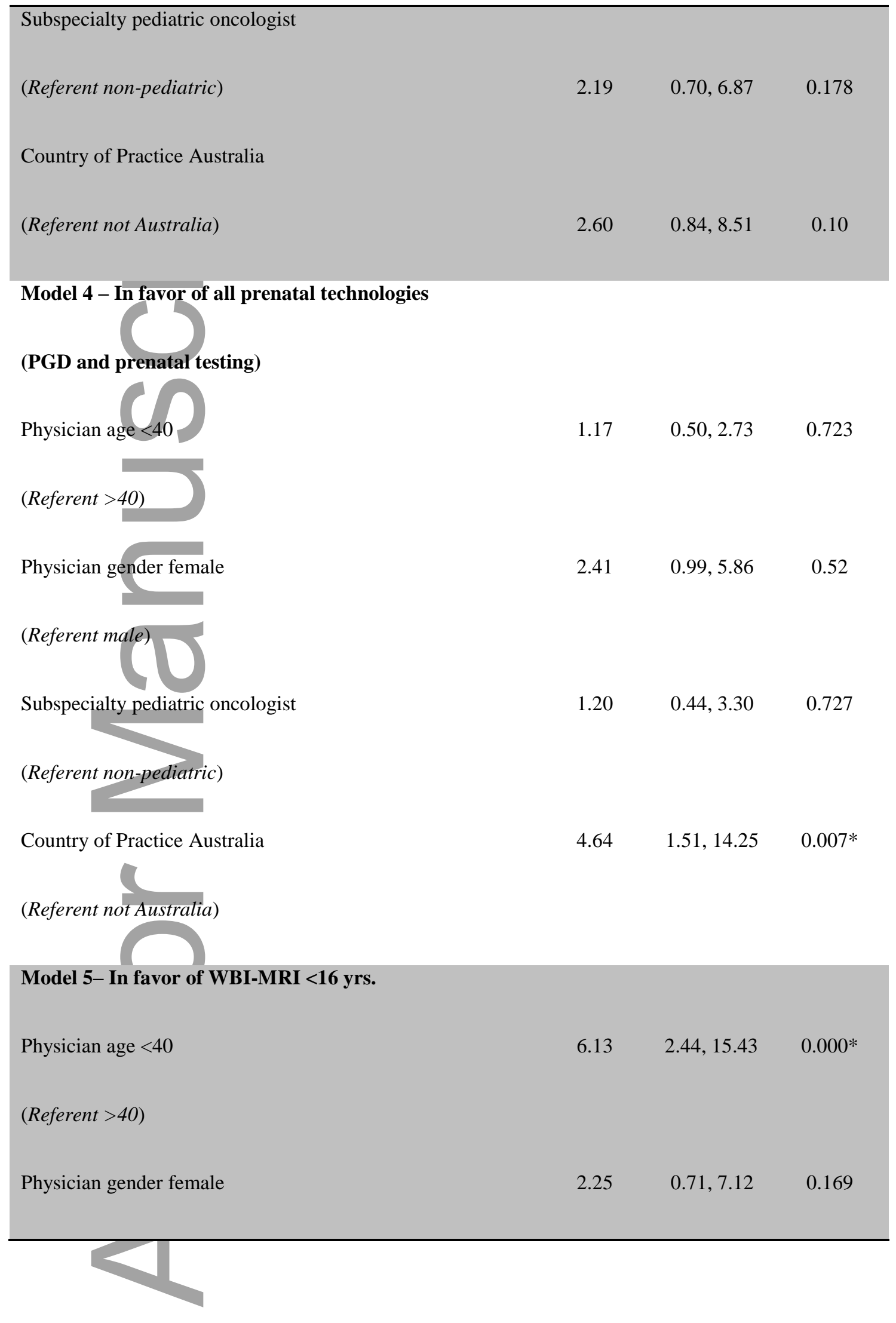

This article is protected by copyright. All rights reserved. 


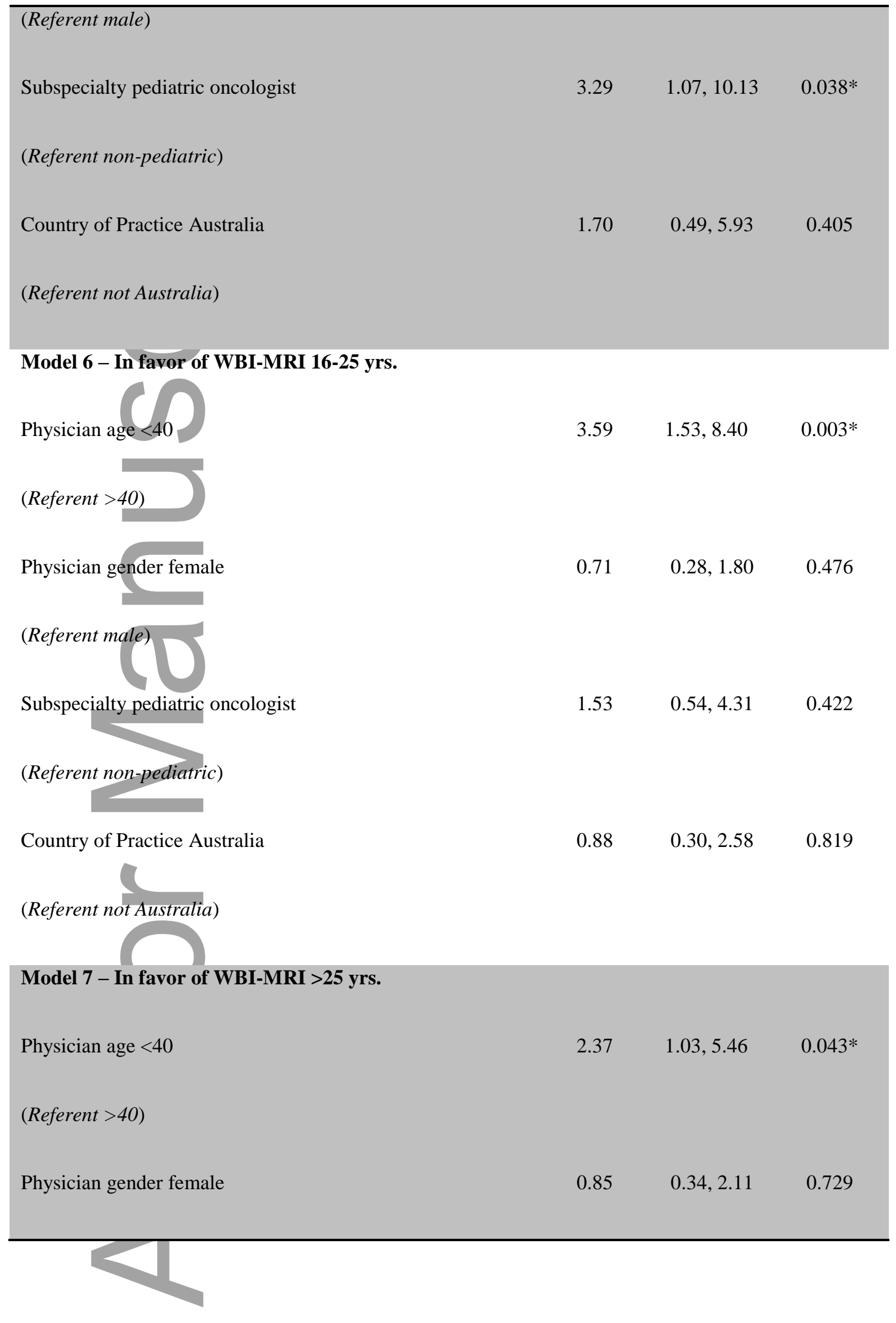

This article is protected by copyright. All rights reserved. 


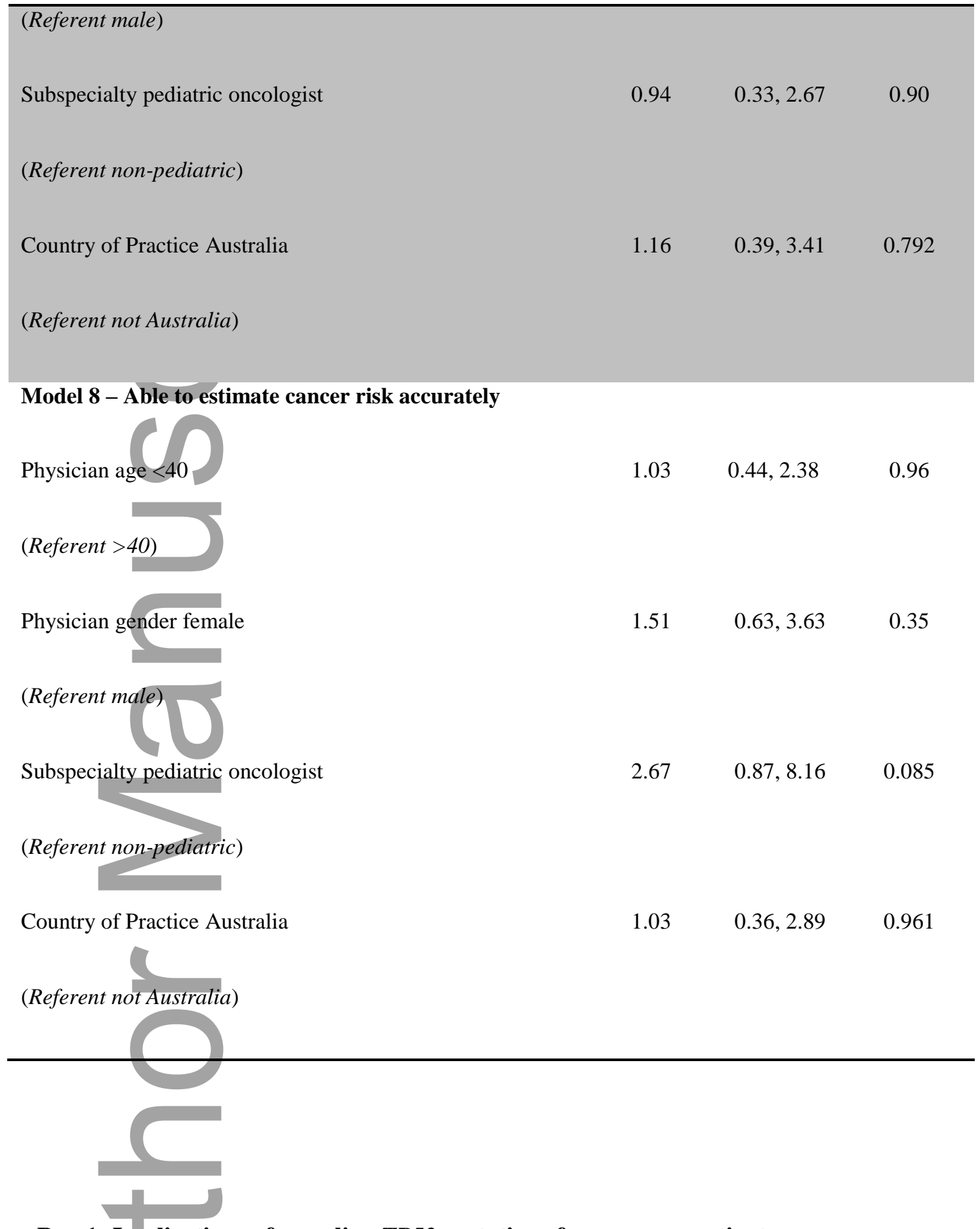

Box 1: Implications of germline TP53 mutations for sarcoma patients

- Potentially 1 in every 30 sarcoma patients carries a germline TP53 mutation regardless of family history (1)

- $\quad$ Germline TP53 mutation are associated with Li-Fraumeni Syndrome (LFS)

This article is protected by copyright. All rights reserved. 
- $\quad$ LFS is a rare cancer syndrome characterized by the high risk of cancer at multiple body sites from early childhood through adulthood (4)

- $\quad 50 \%$ of TP53 mutation carriers identified by family history will develop cancer by the time they are 30 years old (9)

- The most frequent cancers associated with LFS are sarcoma (soft tissue and osteosarcoma), breast cancer, leukemia, adrenal cortical carcinomas and brain tumors (12)

- The cancer risk of relatives of sarcoma patients with a germline TP53 mutation is difficult to quantify as family history is not always a perfect guide

- Germline TP53 mutation carriers have a 57\% probability of a second malignancy within 30 yrs. of an initial cancer diagnosis (13-15)

- $\quad$ TP53 mutation carriers face unique psychosocial challenges given their predisposition for developing several types of cancer. For example, unlike women with germline BRCA1/2 mutations, TP53 mutation carriers may receive little reassurance knowing their carrier status as there is currently only preliminary evidence for effective prevention and/or early detection of TP53 related cancers other than early breast screening or breast cancer preventive surgery in female carriers (1618)

- Ionizing radiation increases cancer risks synergistically although the exact magnitude of risk is unknown $(19,20)$.

- Identification of cancer risk alleles will be important for people with sarcoma for future surveillance measures and reproductive decisions

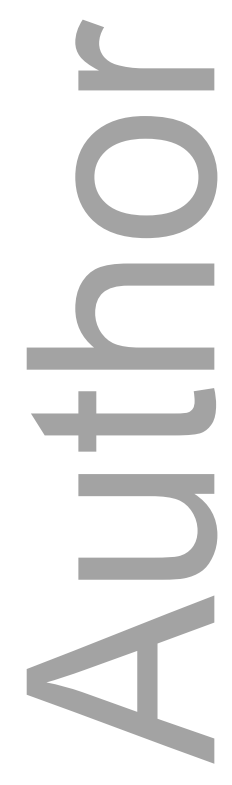

This article is protected by copyright. All rights reserved. 


\section{University Library}

\section{- M M N E R VA A gateway to Melbourne's research publications}

Minerva Access is the Institutional Repository of The University of Melbourne

Author/s:

McBride, KA;Schlub, TE;Ballinger, ML;Thomas, DM;Tattersall, MHN

Title:

International survey of awareness of genetic risk in the clinical sarcoma community

Date:

2016-06-01

Citation:

McBride, K. A., Schlub, T. E., Ballinger, M. L., Thomas, D. M. \& Tattersall, M. H. N. (2016). International survey of awareness of genetic risk in the clinical sarcoma community. ASIAPACIFIC JOURNAL OF CLINICAL ONCOLOGY, 12 (2), pp.133-142. https://doi.org/10.1111/ ajco.12457.

Persistent Link:

http://hdl.handle.net/11343/290990 